\title{
Systematic review of the behavioural assessment of pain in cats
}

Journal of Feline Medicine and Surgery $1-17$

(C) ISFM and AAFP 2015

Reprints and permissions:

sagepub.co.uk/journalsPermissions.nav DOI: 10.1177/1098612X15578725 jfms.com

(S)AGE

\author{
Isabella Merola and Daniel S Mills
}

\begin{abstract}
Objectives The objectives were to review systematically the range of assessment tools used in cats to detect the behavioural expression of pain and the evidence of their quality; and to examine behavioural metrics (considering both the sensory and affective domains) used to assess pain.

Methods A search of PubMed and ScienceDirect, alongside articles known to the authors, from 2000 onwards, for papers in English was performed. This was followed by a manual search of the references within the primary data sources. Only peer-reviewed publications that provided information on the assessment tool used to evaluate the behavioural expression of pain in cats, in conscious animals (not anaesthetised cats), were included.

Results No previous systematic reviews were identified. One hundred papers were included in the final assessment. Studies were primarily related to the assessment of pain in relation to surgical procedures, and no clear distinction was made concerning the onset of acute and chronic pain. Ten broad types of instrument to assess pain were identified, and generally the quality of evidence to support the use of the various instruments was poor. Only one specific instrument (UNESP-Botucatu scale) had published evidence of validity, reliability and sensitivity at the level of a randomised control trial, but with a positive rather than placebo control, and limited to its use in the ovariohysterectomy situation. The metrics used within the tools appeared to focus primarily on the sensory aspect of pain, with no study clearly discriminating between the sensory and affective components of pain.

Conclusions and relevance Further studies are required to provide a higher quality of evidence for methods used to assess pain in cats. Furthermore, a consistent definition for acute and chronic pain is needed. Tools need to be validated that can detect pain in a range of conditions and by different evaluators (veterinary surgeons and owners), which consider both the sensory and emotional aspects of pain.
\end{abstract}

Accepted: 26 February 2015

\section{Introduction}

Pain is an unpleasant sensory and emotional experience associated with actual or potential tissue damage or described in terms of such damage. ${ }^{1}$ As such, it involves far more than mere sensation; ${ }^{2}$ it is a psychological state comprising three domains: sensory-discriminatory (intensity, location and duration of the pain), affectivemotivational (emotional, unpleasantness and aversive aspects of pain) and cognitive-evaluative (evaluation of consequences of pain upon quality of life [QoL]). The first two domains often co-vary and are usually processed simultaneously. ${ }^{3}$ In non-human animals the 'sensory-discriminatory' component seems to be focused on a specific bodily sensation (eg, pressure, temperature, burning, etc), which is relatively easily provoked and investigated. By contrast, the unavoidable lack of self-reporting reduces exploration of the affective-motivational domain, which is usually most prominent in chronic situations, ${ }^{2}$ and makes exploration of the third domain even more challenging. The relationship between tissue damage and the reporting of pain experienced is not a simple linear correlation: ${ }^{3}$ pain can occur in the absence of identifiable tissue damage; 4 can present with confusing signs, such as

School of Life Sciences, University of Lincoln, Lincoln, UK

\section{Corresponding author:}

Isabella Merola DVM, PhD, School of Life Sciences,

University of Lincoln, Joseph Banks Laboratories Green Lane,

Lincoln LN6 7DL, UK

Email: imerola@lincoln.ac.uk 
allodynia (sensitisation to normally innocuous stimuli); and can persist after the damage is resolved (persistent after-sensation). ${ }^{5}$ It seems that the emotional aspect has an important influence on the self-report of pain perception, ${ }^{6}$ which is critical to its impact on the wellbeing of the subject experiencing the pain. In human medicine, the context in which pain occurs may also affect the emotional reaction and perception of pain, ${ }^{2}$ with psychiatric disturbance and mood disorder also often present in patients with chronic pain. ${ }^{2}$ This highlights the importance of the affective-motivational domain in the assessment of pain. However, the lack of clear or current evidence relating to these features in non-human animals should not be interpreted as an absence of an emotional component or need to treat it. Instead, in order to provide effective and appropriate pain management for patients, it should encourage more research into pain assessment.

The cat is one of the most popular companion animals, with a global population estimated to be around 600 million, ${ }^{7}$ with an estimated 69 million cats in the USA and 60 million in Europe. ${ }^{8}$ It is now clearly recognised that vertebrates possess the neuroanatomical and neurophysiological components necessary for transduction, transmission and perception of noxious stimuli. However, it is still not clear to what degree different species feel pain with similar quality and intensities. ${ }^{9}$ Despite painful situations being quite common in veterinary practice, pain is still undertreated in cats. ${ }^{10,11}$ Even if veterinarians are becoming aware of the use of analgesia for pain treatment, there is an absence of approved medication for some painful conditions (eg, osteoarthritis [OA]-associated chronic pain), 12,13 as well as misconceptions about analgesic drugs, and reservations about the adverse effects of analgesics. ${ }^{11}$ Furthermore, even though tools have been used to assess pain expression in cats, there still appears to be no consensus on when, and if, to use these tools, and if they really discriminate painful vs non-painful situations and/or different intensities and qualities of pain expression. ${ }^{14,15}$ The lack of agreement seems to stem partly from (i) the ability of cats to mask signs of pain, possibly as a consequence of being a largely solitary prey species, thus reducing potential predator advantage as in other species ${ }^{16}$ - their subtle expression of pain can easily be missed even by diligent observers, ${ }^{17}$ and (ii) a lack of information for cat owners on pain expression, which limits their ability to report consistent behavioural changes reliably, even if they can recognise these changes. ${ }^{18}$ In addition, if the behavioural changes develop gradually during old age, owners tend to consider the changes to be part of the natural ageing of the animal, ${ }^{8}$ and may not associate the changes with pain, even if they notice them.

Assessment of a patient's experience of pain is a critical component of pain management, and patient welfare, especially in situations where the sensory aspect is not evident. Different tools have been used to detect pain in cats, but pain is not a simple construct and it must be recognised that simple measures do not always take into account the multidimensional nature of pain. A useful pain assessment tool should be sensitive to several qualities of pain and ideally be able to: (i) discriminate the presence vs absence of pain; (ii) evaluate both the sensory and emotional aspects of the condition; (iii) discriminate intensity, frequency, duration and quality between different pain conditions (as, eg, acute vs chronic, mild or intermittent pain experience); (iv) evaluate pain in different contexts, or at least clearly state the contexts to which it is limited; (v) be as simple as possible, requiring minimal training and instrumentation (a natural observation, eg, may be the easiest method). Furthermore, to be recommended, the different tools must have documented levels of validity, reliability and sensitivity from high quality, evidence-based studies. However, this information does not appear to be readily available, and so the aim of this report is to review the scientific literature systematically and critically, and synthesise current knowledge in order to evaluate the potential utility and quality of pain assessment tools used in cats. Following the PRISMA guidelines for reporting systematic review (www.prisma-statement. org), the review specifically aims to (i) identify the range of behavioural tools in use and clearly categorise how they have been used and the domain of pain they refer to; (ii) examine the behavioural metrics used to assess pain across tools; (iii) assess the quality of evidence relating to the use of these tools in specific contexts; and (iv) make recommendations for future assessment.

\section{Materials and methods}

\section{Ethics statement}

This project was approved by the University of Lincoln's local ethics committee. There was no requirement to preregister the review protocol.

\section{Search methods}

Published reports of clinical trials evaluating pain expression through assessment tools in cats with different diseases or conditions were collected through a document search of two electronic databases - PubMed and ScienceDirect - using the keywords 'Cat' and 'Pain', and, as an additional filter, 'other animals'. Databases were accessed from 15-30 February 2014. The references of all identified studies were inspected for additional papers.

\section{Study selection}

Inclusion and exclusion criteria for study selection were predefined to minimise the risk of bias. 
Inclusion criteria Studies had to be in English and be published as a peer-reviewed publication since 2000. They had to provide information on the assessment tool used to evaluate the behavioural expression of pain in cats; the study also had to be on conscious animals (not anaesthetised cats).

Exclusion criteria If the study was a narrative review, a comment, an abstract or a summary, had fewer than five participants, or fewer than five cats showing signs of pain, it was excluded and was not investigated for references. If the study did not describe an assessment tool or did not refer to it in the results, or was referring only to the assessment of QoL it was also excluded. If pain was assessed as part of a QoL measure, only the specific data regarding pain were extracted.

Methodological issue in reviewing the assessment tools for pain We define the type of tool according to the specific approach used (eg, numerical rating scale [NRS], to collect information about the behavioural expression of pain in cats. To assess pain a tool could refer to behavioural changes and physiological parameters, but we focus in this report only on the behavioural elements. The subtype of a tool was the specific instrument used within a given type; for example, the specific form of NRS used. To detect the behavioural changes, metrics within the assessment tools refer to the specific behavioural measurement used. For the metrics used, we discriminated between those using objective observation to record a response (eg, measures such as 'purring when stimulated', 'meows when interacting with the observer', or change in activity levels, etc) ${ }^{19,20}$ and those requiring the observer to make an inference from their observations of the subject (eg, measures such as 'a happy cat', 'comfortable', 'peaceful' or 'cat looks miserable and cannot be touched', etc). ${ }^{21,22}$ The term 'mixed' was used when the scale used a combination of objective and interpretative metrics to differentiate different points on the scale (eg, pupils dilated or not, but movement considered normal or abnormal). ${ }^{23}$

The assessment tools were classified into two categories according to the domain of pain on which they were focused primarily: sensory and sensory-affective. The sensory domain is, by definition, referring to the location and intensity of the pain. We considered a tool to be focused on the sensory domain if it was referring to (i) a local region of the body (eg, focusing on lameness); (ii) an intensity scale (eg, visual analogue scale [VAS] or NRS related to the magnitude of pain; eg, no pain vs maximum pain) not providing information about pain characteristics and impact on the individual; ${ }^{24,25}$ (iii) a provoked response (eg, jumping away, paw withdrawal) - provocation meant any form of interaction with the animal (either direct human contact or instrumental interaction; eg, wound palpation or thermal stimulation). Tools classified as referring mainly to the sensory domain could include some aspects of the affective component such as inferred emotional state, but they were focused primarily on the sensory reaction.

All other tools were related to both sensory and affective domains; none focused primarily on the affective domain.

The affective domain was further classified into:

1 Emotional state - this describes the immediate affective response to pain and consists of four components: ${ }^{26}$ the communication signals issued in response to pain, the change in general arousal caused by the pain, the subsequent behavioural tendencies of the animal (withdrawal, avoidance of contact, etc) and any specific appraisal of the sensation linked to its emotional content (this last component is integrally related to the sensory domain).

2 Mood states - that is, enduring episodic changes in underlying affective predisposition arising as a result of a series of emotional events of congruent emotional valence; for example, a tendency to be irritable from time to time as a result of pain.

3 Temperament - that is, a general disposition or trait that is consistent across time and contexts. This indicates that the pain is persistent, or relief is only temporary, and that a state of pain has become an integral part of the animal's constitution and its behavioural predispositions have shifted accordingly to adapt to the impact of this. For example, a cat in chronic pain might be described as jumpy or irritable the whole time. ${ }^{26}$

Finally, the specific behaviours assessed (metrics) included in the tool were also recorded.

\section{Further data collection and evaluation}

The causes of pain described and the time from when the pain started, together with any definition of acute or chronic pain, were recorded in addition to the total number of cats and their sex distribution. Three measures of performance were considered: validity, reliability and sensitivity. Validity is concerned with whether the instrument measures the characteristic it purports to measure. It is often divided into content (the extent to which a measurement reflects the specific intended domain of content), construct (interpreted as a measure of some attribute or quality that is not 'operationally defined') and criterion validity (demonstrable agreement with another measure or procedure that has been demonstrated to be valid). ${ }^{27}$ Reliability is concerned with the consistency of an instrument. It should produce the same results after re-testing, and is usually 
divided into internal consistency (the consistency of the results delivered in a test, ensuring that the various items measuring the different constructs deliver consistent scores); intra-rater (the degree of stability observed when a measurement is repeated under identical conditions by the same rater); inter-rater (the equivalence or agreement among different raters who are collecting data); and test-retest (the degree of stability when presenting the same task to the same subjects two or more times). ${ }^{28}$ Sensitivity is defined as the ability of the tool to detect any change and to identify a cut-off point on the scale (eg, to identify the point for rescue analgesia for each subject). Responsiveness (sensitivity to change) is an aspect of sensitivity that describes the specific ability of the tool to address meaningful change of clinical importance or relevance. ${ }^{29}$

Furthermore, the study design (experimental or observational) was considered. Experimental studies were further divided into randomised controlled trials (RCTs), controlled clinical trials and clinical trials, which were either of a 'pre- and post-' design (such as pre- and postsurgery), or a postintervention assessment design. Observational studies were divided into cohort studies, case-control studies, cross-sectional studies and case series.

When assessing the quality of the instruments used to assess pain, the documentation of specific tests relating to validity, reliability and specificity were of most importance. To assess the quality of the validity of the instrument, we evaluated how the authors assessed content validity for the tool (expert evaluation, owner records, etc) and for criterion validity the gold standard used alongside any other tools with which it showed convergence. Finally, it was noted if this was undertaken as a blinded procedure. The rigour with which reliability and sensitivity were evaluated was further determined from the design of the study; that is, type of study, use of controls and blind observers, and so on. Only RCTs with a negative control and a blind observer study design were evaluated as providing an adequate level of evidence for objectively assessing the reliability and sensitivity of the instrument.

As part of the evaluation of the usability of the test, the necessity to familiarise/train the cats, or to train the observer for each tool was also noted.

\section{Results}

Results from the search of the two databases produced 300 papers. Of these, 12 records were duplicated and were eliminated. Seventy-six articles were excluded because they were narrative reviews; 69 were excluded because they had five or fewer subjects expressing signs of pain in the report; and 37 were excluded because they were not related to pain. Of the remaining 106 papers, 43 were excluded because they did not describe an assessment tool or did not refer to it in the results, or were referring to just the assessment of QoL. This left 63 articles, and the references cited in each of these that had been published since 2000 were reviewed; 37 papers were added to the list for the final review. One article was considered as two different studies because it included two different populations. This meant a total of 100 articles were analysed (Figure 1).

\section{Subject information}

Cats of both sex, neutered and entire, were included (eight papers did not report sex information); ${ }^{30-37}$ there were more females $(n=2262)$ present in the data than males $(n=1125)$. Breed and age were not always stated, so it could not be assumed that all breeds and ages were represented.

\section{Causes of pain}

See Table S1 in the Supplementary material for references.

The causes of pain reported were as follows. Fortytwo studies were related to surgical causes: 24 to neutering, ${ }^{22,23,31,37-57}$ six to onychectomy/tenectomy; ;0,35,58-61 four to neutering and onychectomy; ${ }^{34,62-64}$ three to fracture repair; $32,65,66$ and five to a variety of other surgeries. ${ }^{21,36,67-69}$ One study evaluated pain during intravenous catheter introduction. ${ }^{70}$ Thirty-five studies were specifically designed to assess the effects of different therapies and/or to investigate the ability to detect pain with different tools (eg, thermal threshold); ${ }^{33,71-104}$ of these 35, six used either a kaolin injection $(n=5)$ or sodium urate injection $(\mathrm{n}=1)$ to induce an inflammatory reaction as a cause of pain. Of the remaining 22 articles: 19 were related to orthopaedic situations (six degenerative joint disease, six OA, five lower limb musculoskeletal disease, one spondylosis and one intervertebral disc disease); $;, 14,15,19,20,76,104-115$ one further study was related to otoacariasis; ;16 one to lower urinary tract disease; ${ }^{117}$ and one to upper respiratory tract disease (URTD). ${ }^{50}$

\section{Time of presenting signs}

Fifty-seven studies were related to the response to deliberate surgeries or provoked pain; that is, the response was assessed immediately after insult for a variable length of time. Of the remaining 22 papers, only four reported the time when the cat had started to express signs of pain. ${ }^{104,106,108,109}$ One study reported signs from no more than 14 days, ${ }^{106}$ describing this as 'acute pain', while another referred to pain of $<8$ weeks' duration as acute, ${ }^{109}$ and two studies referring to chronic pain used subjects reporting signs for $>2$ months or at least 1 month, respectively. ${ }^{104,108}$

\section{Tool type and subtype}

See Table S2 in the Supplementary material for a full list of references. 


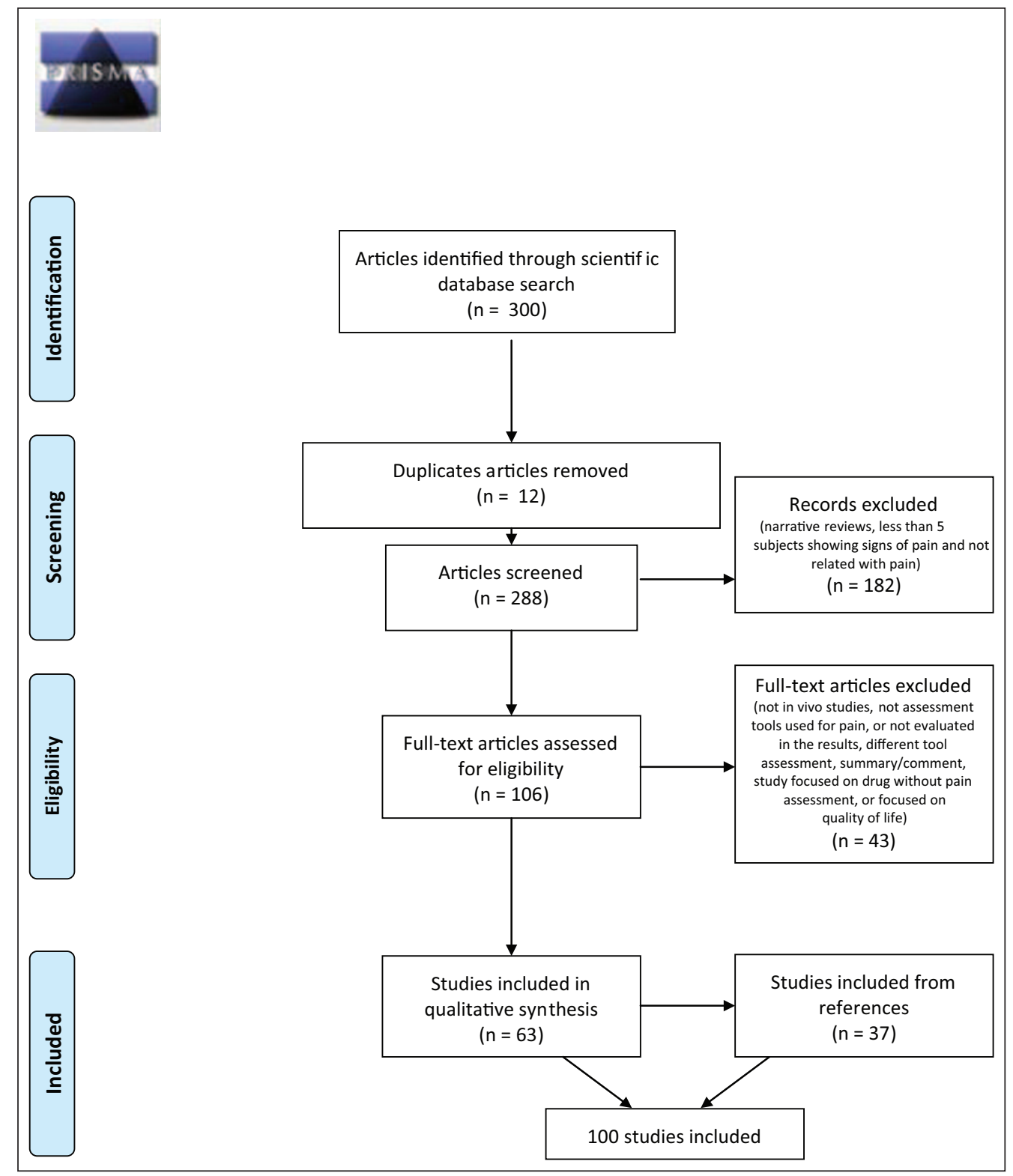

Figure 1 Information considered at different phases of the systematic review. The number of records identified, included and excluded, and the reasons for exclusions, in accordance with PRISMA guidelines (www.prisma-statement.org)

Ten tool types were identified:

1 VAS, consisting of three subtypes (general VAS [gVAS], interactive VAS [IVAS] and dynamic IVAS). These are focused on providing a measure of pain intensity along a single scale; eg, no pain to maximal pain. ${ }^{30,39,44,118}$

2 NRS, consisting of 15 subtypes (eg, a general NRS similar to the gVAS but with the scale divided into numerical units; a simple descriptive scale where each number is associated with a specific definition [these may relate to specific facets, eg, lameness, response to palpation, etc, and be summed to create an overall score]). These scales are used in a wide variety of contexts with both the sensory and affective domains of pain evaluated in this way. $30,32,38$

3 Descriptive rating scale, consisting of four subtypes (eg, feline musculoskeletal pain index). ${ }^{17,111}$ In these, the rating indicates the description that best describes some aspect of the pain of the cat and this may then be allotted a score. Multidimensional assessment of both the sensory and affective domains of pain may be undertaken with these scales. ${ }^{107,111,113}$ 
4 Thermal provocation pain tools, consisting of two subtypes (thermal threshold [TT] test ${ }^{75,81,88}$ and radiant emitter mat test ${ }^{63,80,84}$ ). These provide a unidimensional measure of the sensory reaction, looking at the temperature necessary to result in withdrawal.

5 Pressure-provoked pain tools, consisting of 11 subtypes (eg, pressure threshold [PT] test, ${ }^{71,73,92,94}$ mechanical nociceptive threshold tests, ${ }^{32,44,45}$ response to orthopaedic manipulation, ${ }^{115}$ etc). These provide a unidimensional measure of the provoked sensory reaction, looking at the pressure necessary to result in withdrawal.

6 Pressure measurement mat, consisting of two subtypes (the peak vertical force measurement ${ }^{105}$ and pressure platform mat ${ }^{58,64,118}$ ). These provide a unidimensional measure of sensory pain in a local region by indicating the force being used by a painful limb.

$7 \quad$ Electric provoked pain tools (no subtypes). These provide a unidimensional measure of the provoked sensory reaction, looking at the electricity necessary to result in withdrawal. ${ }^{94}$

8 Owner report (no subtypes). This is a qualitative report from the primary carer and may provide multidimensional measures of both the sensory and affective domain of pain. ${ }^{117}$

9 Behavioural observation (no subtypes). The frequency and/or duration of certain behavioural measures can provide information on both the sensory and affective domains of pain. ${ }^{35,54}$

10 Motor activity assessment (no subtype). This largely provides a unidimensional measure of the inhibition caused by sensory pain in a local region. ${ }^{105,107,110,111}$

NRS scales were the most common tool, used in 53 studies, while VAS and thermally provoked pain tools were used in 30, pressure-provoked pain tools in 27, a descriptive rating scale in 12 , pressure measurement mat in four and activity motor in four. Behavioural observation was reported in two studies, and owner report and electrical threshold in only one study each (see Table S2 in the Supplementary material).

Looking at the tool subtypes in total, 25 related primarily to the sensory aspect of pain (provoked reaction, local region and intensity), while 19 related to both sensory and affective domains. Only for the general NRS and simple descriptive scale (SDS) tool subtype were the domains investigated mixed (see Table S2 in the Supplementary material).

\section{Quality of the assessment tool subtypes}

Of the 100 studies explored, 25 studies were aiming to develop and validate a tool subtype able to assess pain in cats. $18,20,30,33,35,38,41,43,44,54,55,58,73,74,76,77,82,95,97,101,105,110,111,113,114$
Of all the tool subtypes reported, only the UNESPBotucatu composite pain scale ${ }^{41}$ which refers to both the sensory and affective domains of pain, reported on all three quality measures; that is, validity, reliability and sensitivity (referring also to its responsiveness). The scale was evaluated for content, construct and criterion validity. All items scored higher than 0.5 , in agreement with the expert evaluation (content); at the same time, good criterion validity was evaluated between blind observers and the gold standard; a high correlation with the IVAS scale $(r=0.87, P<0.001)$ for all blinded observers was evident (concurrent validity); and good construct validity was apparent from clear hypothesis testing. At the same time, the tool was evaluated for internal consistency, and intra- and inter-rater reliability. Cronbach's $\alpha$ coefficient for the three dimensions was excellent for both the subscales relating to 'pain expression' and 'psychomotor change' $(r=0.86-0.87)$ but indicated inconsistency with physiological variables $(\mathrm{r}=$ 0.28) (internal consistency); good agreement among blind observers was evidenced (confidence interval between 0.70 and 0.98 in relation to the behaviour analysed), and good agreement between the same observer after 1 month (inter- and intra-rater). The sensitivity and the specificity of the tool was $>96.5 \%$, with a cut-off point $>7$ (scale range $0-30$ ), indicating excellent discriminatory ability. The sensitivity to change (responsiveness) was evaluated, looking at the absolute (differences between pre- and post-design) and the percentage decrease in pain scores after analgesia had been applied over an extended timeframe. This tool was evaluated in an RCT of ovariohysterectomy with a positive control (fentanyl) and blind observers. Furthermore, use of the tool did not require the cats to be trained, or for them to be evaluated, and only general guidance was given to the pain assessors, rather than specific training.

\section{Metrics (see Tables 1-3)}

The specific behaviour measures provided for each tool subtypes were evaluated. For two of these subtypes, no information was available and these tools were excluded from further consideration. . 3,76

\section{Metrics of the subtypes related primarily to the sensory component}

For 12 tool subtypes related to the sensory domain that reported the metrics used to assess the pain, the authors did not specifically define the behavioural reaction to be measured. 19,30,38,42,44,48,104,107,109,115,116,118 For the subtypes that reported the metrics, the behaviours principally represented were flitching/twitching of the skin, turning head towards stimulus/apparatus, the tendency to try to bite/lick the apparatus or its surface, jumping or moving away, leg/paw shake or withdrawal, and flicking of the tail (see Table 1 for further details). Although these 


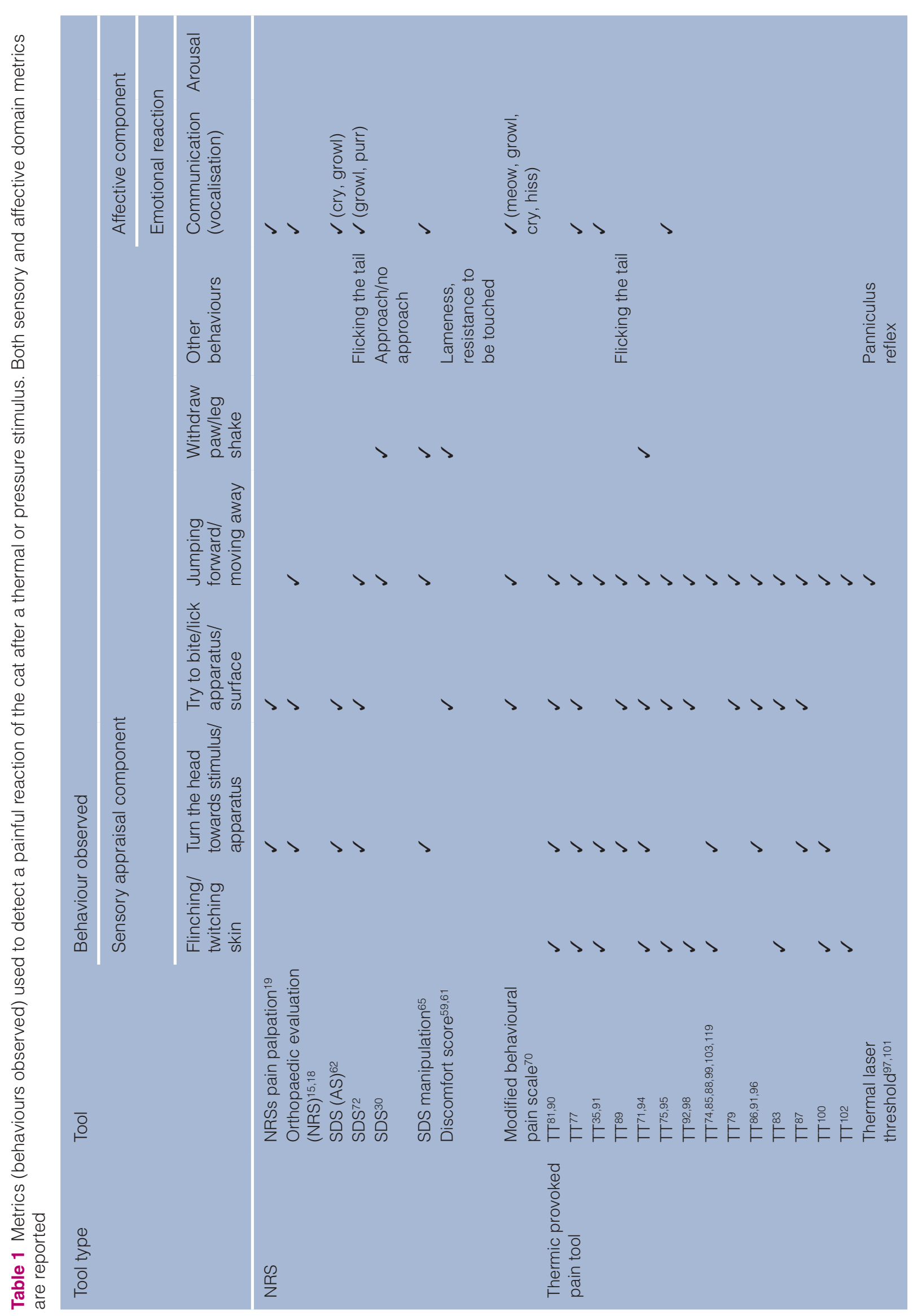




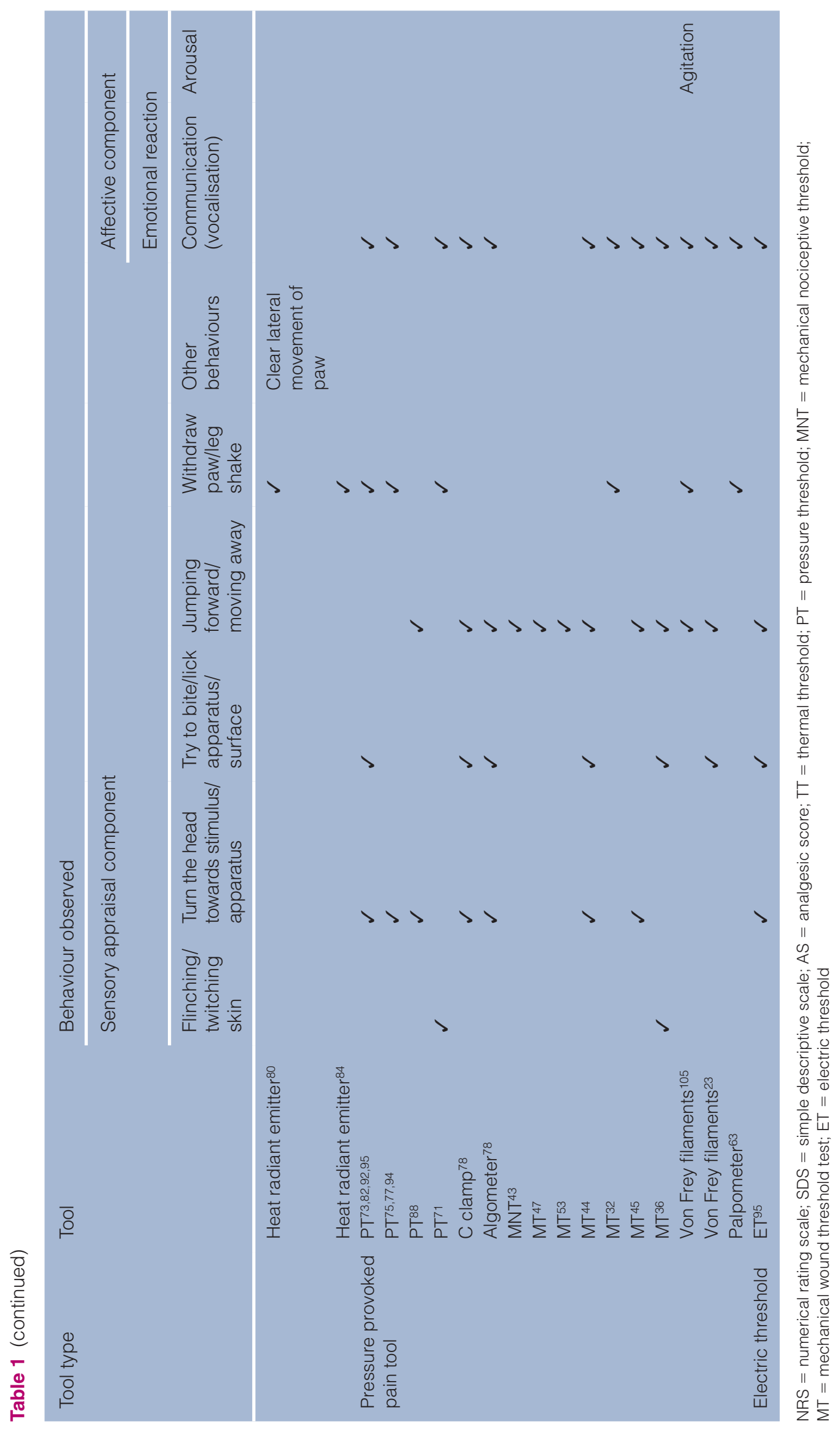




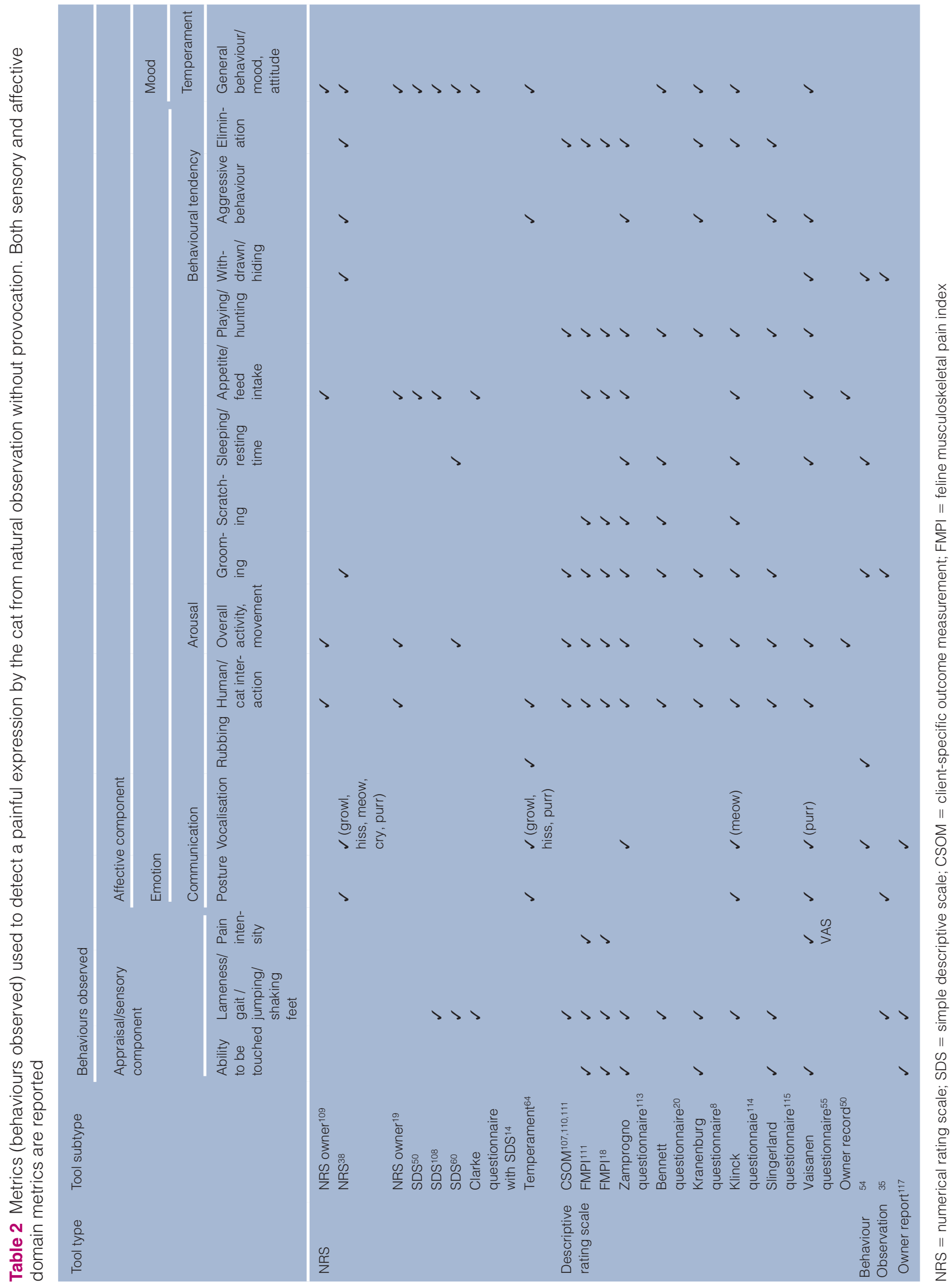




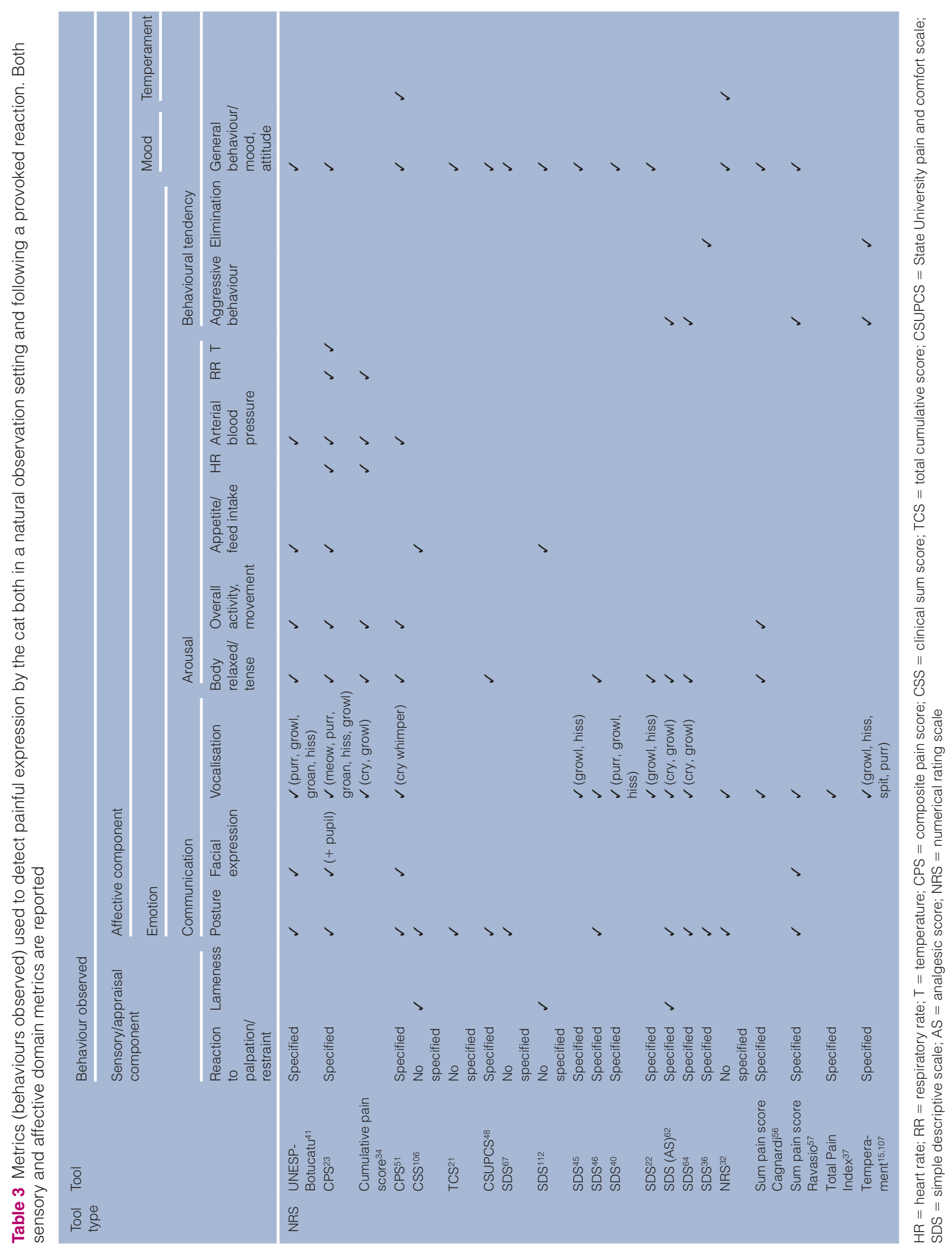


subtypes were focused on the sensory/appraisal domain (nociception of pain), the tool included few other aspects of the affective domain. In particular, most of them evaluated the vocalisation behaviour of the cats (but only three tool subtypes specified what type of vocalisation they were looking at ${ }^{62,70,72}$. Moreover, only one tool subtype looked at another aspect of the affective component, ${ }^{105}$ looking at the general agitation of the subject (arousal) (see Table 1 for distribution of provoked reaction metrics). These subtypes used objective observation to record a response (ie, description of the cat's reaction).

\section{Metrics of the subtypes related primarily to both the sensory and affective components}

These metrics are reported in Tables 2 and 3. The subtypes related to both domains were used in different contexts in different studies: some studies used these tools while observing the animal's behaviour without interference with the subject, $8,14,19,20,35,38,50,54,55,60,64,107-111,113-115,117$ while others used them while both observing the natural behaviour and interacting with the subject; $15,21-23,32,34,36,37,40,45,46,48,51,56,57,62,64,67,106,107,112$ these tools are reported in separate tables (Tables 2 and 3). The metrics principally used (ie, in at least 11 of the 20 subtypes using this type of metric) relating to natural observation were lameness/gait/jumping, grooming, human-cat interaction and overall activity, appetite/food intake and general mood. By contrast, the metrics principally used (ie, in at least 11 out of the 21 subtypes using this type of metric) relating to both natural and provoked observation were reaction to palpation/restraint, posture, vocalisations, body tension and general mood/behaviour. For all 41 subtypes reporting the metrics evaluated for both domains, 16 used objective observation to record a respo nse, $, 1,19,20,34,35,38,50,50,54,60,107,109,110,113-115 \quad 12$ required the observer to make an inference from their observation, $15,21,22,36,40,45,46,56,57,62,64,67$ while 12 appeared to have mixed categories. ${ }^{14,18,23,32,41,48,51,55,106,108,111,112}$

\section{Discussion}

In this systematic review, the range of behavioural-based assessment tools used to assess pain in cats was identified and evaluated. The detection of pain is one of the most challenging problems in medicine and biological studies; ${ }^{30}$ but, if not detected, pain can increase the morbidity and mortality risks of the subject. ${ }^{30}$ The importance of using validated pain assessment tools has received more attention in recent years; ${ }^{120}$ however, in non-human animals the reporting of pain is always by a proxy and not the subject experiencing the pain, which adds a further level of complexity to assessing the needs of the patient. Thus, the validity, reliability and sensitivity of the tool used are particularly important, and it should be applicable in a range of contexts rather than related to a specific situation, although there may be at least three broad pathologies giving rise to pain:12 nociceptive, when there is no inflammation or nervous system damage; inflammatory, when there is active inflammation; and neuropathic, when the nervous system is damaged.

Only peer-reviewed papers related to pain expression with in vivo experimental procedures on cats were selected, but still 100 papers were identified as suitable for inclusion. Many focused on provoked (acute) pain situations, such as neutering surgery or a thermal threshold test, with other studies $(n=22)$ referring to pain in other contexts (of these, 17 were related to orthopaedic situations). By contrast, the literature relating to pain suggests a much wider range of conditions giving rise to pain. For example, diseases such as lower urinary tract disease, pancreatitis, inflammatory bowel disease, cholangiohepatitis, pleuritis, upper respiratory tract infections and obstipation have all been suggested to give rise to acute pain, as have conditions more broadly associated with dermatological, ocular and urogenital systems. ${ }^{120}$ Degenerative joint disease, interstitial cystitis, various cancers, and many dermatological, dental and oral diseases such as gingivostomatitis, slow healing wounds, burns and diabetic neuropathy have all been suggested as causes of chronic pain. ${ }^{12}$ However, this review has highlighted the limited range of conditions in which tools aimed at assessing pain in a structured way have been employed. This might be because the controlled evaluation of pain may be easier in a scheduled condition such as a routine surgery protocol. However, the significance of this gap in the literature needs to be acknowledged as pain (nociceptive, inflammatory or neuropathic) arising in different circumstances may not only have different specific expressions, but may also be experientially different. Nonetheless, the basic features of the affective response, such as unconditioned facial expressions, may provide a basic platform on which this diversification occurs. ${ }^{121,122}$ It may be that by grounding development more thoroughly in such psychobiological processes, a more general pain assessment tool can be developed; at present, it seems development is often grounded by pragmatic requirements or assessment of the localised (sensory) response. In conclusion, there is currently no adequate pain assessment tool that has been shown to be valid across a wide range of situations.

This review also highlights that there does not appear to be a consistent definition of acute and chronic pain in relation to the duration of signs. The only four studies reporting on this (two referring to acute pain and two referring to chronic pain ${ }^{104,106,108,109}$ ) overlapped in the time courses they describe. Acute pain is usually described as a temporary feeling that has evolved to allow avoidance of damaging stimuli or stimuli that will interfere with the healing of damaged tissue; ${ }^{123,124}$ by 
contrast, chronic pain extends beyond the expected healing period and limits activity that may exacerbate the damage to weakened or repaired tissue. ${ }^{124,125}$ In the literature reviewed here, the distinction between acute and chronic pain appears to be arbitrary, with the transition from acute to chronic being variously placed at a few days to several weeks. ${ }^{124}$ Lascelles and Robertson have suggested that defining pain as chronic or acute based on its duration fails to recognise its underlying causal factors; ${ }^{12}$ these authors propose that the terms 'adaptive' for acute pain and 'maladaptive' for chronic pain may be preferable, as this reflects the capacity of the body to avoid the stimulus. Our review indicates that all of the tools examining pain in a provoked situation (acute), such as neutering surgery, primarily focused on the sensory domain of pain, while those tools examining pain in other conditions (more typically thought of as chronic, eg, degenerative situations), focused primarily on the affective domain. Therefore, it seems that the emotional aspects of pain are more widely recognised in the longstanding context. We suggest that rather than focus on either the duration of pain or its putative adaptive value, it may be preferable to focus attention on the extent to which signs relate to the sensory or affective domains. We hypothesise that this may help not only to identify important qualities of pain in a more systematic way, but also to provide a more rational basis for different forms of analgesic intervention.

Ten types of assessment tools were identified: three referring to pain scales (VAS, NRS and descriptive rating scales), four referring to quantitative sensory testing (TT, PT, pressure mat and electric threshold), one looking at the owner report, one referring to the frequencies of behaviours and one related to the motor activity. Of these, the NRS, the VAS and the TT were the most representative in all of the studies.

Few tool subtypes reported to any degree the validity, reliability and sensitivity for the tool. As we described before, an ideal assessment tool should focus on the aspect that needs to be detected, be highly sensitive, have minimal variability among observers and conditions, and should not require training for the assessor and for the subject in which the pain is assessed. Following these criteria only the NRS subtype UNESPBotucatu scale (English version) evidenced (in an RCT with a positive control and blind observer) a good validity (a low internal consistency was found for the physiological variables but this did not affect the tool validity), reliability and sensitivity (with responsiveness). This tool did not require the cats to be trained, with guidance given only to the observers that were using the tool (not the owner). However, there were a few limitations of this scale: (i) to evaluate the criterion validity the author used a comparative scale (IVAS) that is still not validated; (ii) the sensitivity/responsiveness was evaluated in an RCT study design but without a negative control; (iii) the tool has been used only in the context of ovariohysterectomy, with no other studies evidencing its validity in other pain conditions; (iv) the assessors were all persons working with animals, and no 'non-expert' (eg, owners) used the scale. These points highlight the need for further work on this assessment tool for it to be considered a valid assessment instrument of pain.

In relation to the sensory appraisal vs affective domains they were referring to, no tool subtypes described the metrics used to assess pain. When assessing emotion such as pain, four distinct components (appraisal domain, communication, arousal and behavioural tendency) need to be evaluated. ${ }^{26}$ Most tool subtypes referred (not explicitly) only to the sensory/ appraisal aspect of pain expression and few to aspects of the affective components (eg, vocalisation as a form of emotional communication). This result reflects the lack of attention given to the affective domain when using a tool that is focusing on a provoked pain reaction (TT, PT, etc). Furthermore it is important to highlight that these tools often require substantial habituation by the cats, limiting the sample size and generalisation of the method. For these two main reasons, tools focusing only on the sensory domain of pain - even if reliable - cannot be suggested to be a general pain assessment instrument, but only sensory and nociceptive pain indicators (eg, they might be able to detect phenomena such as hyperalgesia but less clearly the impact of pain on the animal's wide perceptions)

Only 19 tool subtypes (in 46 studies) referred to both domains of pain (primarily looking at the affective component). In 23 studies these were linked to some form of provocation test (eg, palpation) to assess pain, while in the other 23 they considered only the spontaneous behaviour.

Different authors are generally in accord that it remains important not only to observe the undisturbed animal, but also to interact with, move around and palpate the affected area in order to complete a picture of how much pain the animal is in. ${ }^{11}$ Unfortunately, cat interaction can invoke a range of other emotional states in the subject, such as fear and frustration, as well as further pain. Further damage of the tissue will elicit avoidance or attack as a result of further pain, while the presence of the experimenter might provoke a fear of either pain or of the experimenter, while frustration may arise because the cat cannot avoid the situation and access a place of safety. These other emotions are important but could complicate the assessment of pain per se if not considered separately. Hence, the tools requiring a provoked reaction for pain assessment (including the UNESP-Botucatu scale), even if they give more information on the affective component of pain, compared with ones focused only on the sensory aspect (eg, TT), cannot 
be suggested to meet the requirement of a global gold standard tool (eg, an owner cannot use these tools to assess pain in their cat).

A natural observation tool seems, by contrast, to be a better assessment tool. Behaviour is cited as one of the most effective and non-invasive routes by which pain can be assessed. ${ }^{126}$ Even if the ability to recognise behavioural indicators of pain may depend on familiarity with the species by the assessor, ${ }^{127}$ and this assessment can be considered relatively subjective and to contain inherent bias when there is a lack of objective criteria to judge it, ${ }^{128}$ a well-validated pain behavioural assessment tool could permit an easier clinical evaluation and even an owner identification. In fact, owners seem able to recognise behavioural changes but often do not report on these, ${ }^{18}$ considering sometimes the changes to be part of the natural ageing of the animal. ${ }^{8}$ From our results, no tool subtypes related to a natural observation were valid, reliable and sensitive. However, looking at the studies that used a tool subtype focused on natural observation (and primarily on the affective component of pain), some metrics were consistently identified: lameness/gait/ jumping, human-cat interaction, grooming and overall activity, appetite/food intake and general mood. Caution is required in interpreting individual indicator behaviours in isolation: although single behaviours may be suitable for simple presence/absence observations (as could a specific facial expression), the use of a combination of pain behaviours produces greater accuracy, ${ }^{129}$ potentially adding information related to both pain domains. When considering how to infer emotion, a systematic process that should reduce the risk of error has recently been described for non-human animals based on assessing the evidence from the four components of emotions. ${ }^{130,131}$ This requires assessing the evidence from each of the following: the context leading to emotional arousal (appraisal), the level and form of arousal, the behavioural tendencies of the animal and the communicative signals associated with the state (including facial expression). If the evidence is clearly contradictory to the hypothesis that the animal is in a given emotional state, then the inference should be rejected.

Another important observation in relation to the metrics used in the behavioural assessment tools is that not all of them used an objective description of the behaviours. Only 16/41 subtypes clearly used completely objective descriptions of behaviour rather than inference. Interpretations of behaviour require the observer to make an inference, which risks reducing the reliability and validity of the scale, and limits the generalisability of the results obtained with the tool. A consensus core of behaviours, which may be taken as reliable expressions of pain in cats, is only just starting to be created: for example Cloutier et al and Waran et al reported the frequencies of some behaviours in RCT study designs with a negative control group. ${ }^{35,54}$ Unfortunately, this core has to be expanded (eg, few authors have reported on facial expression, while none on the behavioural tendency or the mood and temperament aspects of pain in cats) to permit an objective and systematic evaluation, by natural observation, of pain expression.

By way of further suggestions, studies should seek to: (i) assess pain in different conditions in high quality evidence studies; (ii) discriminate between acute and chronic pain, not only in reference to the onset of signs, but also by considering the domain of pain they are referring to; and (iii) validate an assessment tool for the detection of pain in cats in both acute or chronic situations. These tools will have to be focused on both domains of pain (sensory and affective); have an objective definition for the metrics used; assess pain in a natural observation setting; and be able to be used by owners, as well as experts. If a tool refers only to some aspects of pain (eg, the sensory domain or only relates to acute pain), the lack of information on other aspects of pain (eg, the affective domain) needs to be explicitly acknowledged so that end-users do not accidentally use it in inappropriate contexts.

\section{Conclusions}

There is currently no adequate pain assessment tool that has been shown to be valid across a wide range of situations in cats. Further studies are required to provide a higher quality of evidence for methods used to assess pain in cats. Furthermore, a consistent definition for acute and chronic pain is needed, focusing attention on the extent to which signs relate to the sensory or affective domains of pain, rather than focusing on either the duration or its putative adaptive value. Tools need to be validated that can detect pain in a range of conditions and by different evaluators (veterinary surgeons and owners), which consider both the sensory and emotional aspects of pain.

Supplementary material The following files are available: Table S1: The level of evidence and the causes of pain used for tool evaluation in each study.

Table S2: A description of all the tool types and the subtypes evidenced, with the validity, reliability, responsiveness and sensitivity of the related study protocol.

Conflict of interest The authors do not have any potential conflicts of interest to declare.

Funding Feline Friends (Derbyshire) supported this study through the provision of funding, which allowed the employment of IM on this work.

\section{References}

1 Merskey H and Bogduk N (eds). Classification of chronic pain. IASP Task Force on Taxonomy. Seattle: IASP Press, 1994. 
2 Hanse GR and Strelzer J. The psychology of pain. Emerg Med Clin N Am 2005; 23: 339-348.

3 Fernandez E and Turk DC. Sensory and affective components of pain: separation and synthesis. Psychol Bull 1992; 112: 205-217.

4 Chaturvedi SK. Prevalence of chronic pain in psychiatric patients. Pain 1987; 29: 231-237.

5 Craig AD. Pain mechanisms: labeled lines versus convergence in central processing. Annu Rev Neurosci 2003; 26: $1-30$.

6 Craig KD, McMahon RJ, Morison JD, et al. Developmental changes in infant pain expression during immunization injections. Soc Sci Med 1984; 19: 1331-1337.

7 Peterson MN, Hartis B, Rodriguez S, et al. Opinions from the front lines of cat colony management conflict. PLOS ONE 2012: 7; e44616.

8 Kranenburg HC, Meij BP, von Hofwgen EML, et al. Prevalence of spondylosis deformans in the feline spine and correlation with owner-perceived behavioural changes. Vet Comp Orthop Traumatol 2012; 25: 217-223.

9 Paul-Murphy J, Ludders JW, Robertson SA, et al. The need for a cross-species approach to the study of pain in animals. J Am Vet Med Assoc 2004; 224: 692-697.

10 Murrell JC and Johnson CB. Neurophysiological techniques to assess pain in animals (review). J Vet Pharmacol Ther 2006; 29: 325-335.

11 Lascelles BDX, Capner CA and Waterman-Pearson AE. Current British veterinary attitudes to preoperative analgesia for cats and small mammals. Vet Rec 1999; 145: 601-604.

12 Lascelles BD and Robertson SA. DJD-associated pain in cats: what can we do to promote patient comfort? J Feline Med Surg 2010; 12: 200-212.

13 Bennett D, Zainal A and Johnston P. Osteoarthritis in the cat: 2 . How should it be managed and treated? J Feline Med Surg 2012; 14: 76-84.

14 Clarke SP and Bennett D. Feline osteoarthritis: a prospective study of 28 cases. J Small Anim Pract 2006; 47: 439-445.

15 Lascelles BDX, Dong YH, Marcellin-Little DJ, et al. Relationship of orthopedic examination, goniometric measurements, and radiographic signs of degenerative joint disease in cats. Vet Res 2012; 8: 10.

16 Ashley FH, Waterman-Pearson AE and Whay HR. Behavioural assessment of pain in horses and donkeys: application to clinical practice and future studies. Equine Vet $J$ 2005; 37: 565-575.

17 Lamont LA. Feline perioperative pain management. Vet Clin N Am Small 2002; 32: 747-763.

18 Benito J, DePuy V, Hardie E, et al. Reliability and discriminatory testing of a client-based metrology instrument, feline musculoskeletal pain index (FMPI) for the evaluation of degenerative joint disease-associated pain in cats. Vet J 2013; 196: 368-373.

19 Sano T, King JN, Seewald W, et al. Comparison of oral robenacoxib and ketoprofen for the treatment of acute pain and inflammation associated with musculoskeletal disorders in cats: a randomised clinical trial. Vet J 2012; 193: 397-403.

20 Bennett D and Morton C. A study of owner observed behavioural and lifestyle changes in cats with musculoskeletal disease before and after analgesic therapy. J Feline Med Surg 2009; 11: 997-1004.

21 Kamata M, King JN, Seewald W, et al. Comparison of injectable robenacoxib versus meloxicam for peri-operative use in cats: results of a randomised clinical trial. Vet $J$ 2012; 193: 114-118.

22 Giordano T, Steagall PVM, Ferreira TH, et al. Postoperative analgesic effects of intravenous, intramuscular, subcutaneous or oral transmucosal buprenorphine administered to cats undergoing ovariohysterectomy. Vet Anaesth Analg 2010; 37: 357-366.

23 Brondani JT, Loureiro Luna SP, Beier SL, et al. Analgesic efficacy of perioperative use of vedaprofen, tramadol or their combination in cats undergoing ovariohysterectomy. J Feline Med Surg 2009; 11: 420-429.

24 Moore A, Edwards J, Barden J, et al. Bandolier's little book of pain. Oxford: Oxford University Press.

25 Breivik H, Borchgrevink PC and Allen SM. Assessment of pain. Br J Anaesth 2008; 101: 17-24.

26 Mills DS (ed). The encyclopedia of applied animal behaviour and welfare. Cambridge: Cambridge University Press, CABI, 2010.

27 Cronbach LJ and Meehl PE. Construct validity in psychological tests. Psychol Bull 1955; 52: 281-302.

28 Rousson V, Gasser T and Seifert B. Assessing intrarater, interrater and test-retest reliability of continuous measurements. Stat Med 2002; 21: 3431-3446.

29 Corzillius M, Fortin P and Stucki G. Responsiveness and sensitivity to change of SLE disease activity measures. Lupus 1999; 8: 655-659.

30 Cambridge J, Tobias KM, Newberry RC, et al. Subjective and objective measurements of postoperative pain in cats. J Am Vet Med Assoc 2000; 217: 685-690.

31 Kim YK, Lee SY, Park SJ, et al. Feasibility of single-portal access laparoscopic ovariectomy in $\mathbf{1 7}$ cats. Vet Rec 2011; 169: 179 .

32 Möllenhoff, Nolte I and Kramer S. Anti-nociceptive efficacy of carprofen, levomethadone and buprenorphine for pain relief in cats following major orthopaedic surgery. J Vet Med A Physiol Pathol Clin Med 2005; 52: 186-198.

33 Dixon MJ, Robertson SA and Taylor PM. A thermal threshold testing device for evaluation of analgesic in cats. Res Vet Sci 2002; 72: 205-210.

34 Dobbins S, Brown NO and Shofer FS. Comparison of the effects of buprenorphine, owymorphone hydrochloride, and ketoprofen for postoperative analgesia after onychectomy or onychectomy and sterilization in cats. J Am Anim Hosp Assoc 2002; 38: 507-514.

35 Cloutier S, Newberry RC, Cambridge AJ, et al. Behavioural signs of postoperative pain in cats following onychectomy or tenectomy surgery. Appl Anim Behav Sci 2005; 92: 325-335.

36 Hunt JR, Grint NJ, Taylor PM, et al. Sedative and analgesic effects of buprenorphine, combined with either acepromazine or dexmedetomidine, for premedication prior to elective surgery in cats and dogs. Vet Anaesth Analg 2013; 40: 297-307.

37 Anash OB, Vaino O, Hellsten C, et al. Postoperative pain control in cats: clinical trials with medetomidine and butorphanol. Vet Surg 2002; 31: 99-103. 
38 Rohrer Bley C, Neiger-Aeschbacher G, Busato A, et al. Comparison of perioperative racemic methadone, levomethadone and dextromoramide in cats using indicators of post-operative pain. Vet Anaesth Analg 2004; 31: 175-182.

39 Gassel AD, Tobias KM, Egger CM, et al. Comparison of oral and subcutaneous administration of buprenorphine and meloxicam for preemptive analgesia in cats undergoing ovariohysterectomy. J Am Vet Med Assoc 2005; 227: 1937-1944.

40 Staffieri F, Centonze P, Gigante G, et al. Comparison of the analgesic effects of robenacoxib, buprenorphine and their combination in cats after ovariohysterectomy. Vet J 2013; 197: 363-367.

41 Brondani JT, Mama KR, Luna SPL, et al. Validation of the English version of the UNESP-Botucatu multidimensional composite pain scale for assessing postoperative pain in cats. Vet Res 2013; 9: 143.

42 Grint NJ, Murison PJ, Coe RJ, et al. Assessment of the influence of surgical technique on postoperative pain and wound tenderness in cats following ovariohysterectomy. J Feline Med Surg 2006; 8: 15-21.

43 Slingsby LS, Jones A and Waterman-Pearson AE. Use of a new finger-mounted device to compare mechanical nociceptive thresholds in cats given pethidine or no medication after castration. Res Vet Sci 2001; 70: 243-246.

44 Benito-de-la-Víbora J, Lascelles BD, García-Fernández P, et al. Efficacy of tolfenamic acid and meloxicam in the control of postoperative pain following ovariohysterectomy in the cat. Vet Anaesth Analg 2008; 35: 501-510.

45 Polson S, Taylor PM and Yates D. Analgesia after feline ovariohysterectomy under midazolam-medetomidine-ketamine anaesthesia with buprenorphine or butorphanol, and carprofen or meloxicam: a prospective, randomised clinical trial. J Feline Med Surg 2012; 14: 553-559.

46 Glerum LE, Egger CM, Allen SW, et al. Analgesic effect of the transdermal fentanyl patch during and after feline ovariohysterectomy. Vet Surg 2001; 30: 351-358.

47 Slingsby L and Waterman-Pearson AE. Postoperative analgesia in the cat after ovariohysterectomy by use of carprofen, ketoprofen, meloxicam or tolfenamic acid. J Small Anim Pract 2000; 41: 447-450.

48 Catbang DL, Quimby JM, Mama KR, et al. Comparison of the efficacy and adverse effects of sustained-release buprenorphine hydrochloride following subcutaneous administration and buprenorphine hydrochloride following oral trans mucosal administration in cats undergoing ovariohysterectomy. Am J Vet Res 2011; 72: 461-466.

49 Slingsby L and Waterman-Pearson AE. Comparison between meloxicam and carprofen for postoperative analgesia after feline ovariohysterectomy. J Small Anim Pract 2002; 43: 286-289.

50 Lopez S, Pertuy S, Horspool L, et al. Vedaprofen therapy in cats with upper respiratory tract infection or following ovariohysterectomy. J Small Anim Pract 2007; 48: 70-75.

51 Al-Gizawiy MM and P Rudé E. Comparison of preoperative carprofen and postoperative butorphanol as postsurgical analgesics in cats undergoing ovariohysterectomy. Vet Anaesth Analg 2004; 31: 164-174.
52 Tobias KM, Harvey RC and Byarlay JM. A comparison of four methods of analgesia in cats following ovariohysterectomy. Vet Anaesth Analg 2006; 33: 390-398.

53 Bortolami E, Murrell JC and Slingsby LS. Methadone in combination with acepromazine as premedication prior to neutering in the cat. Vet Anaesth Analg 2013; 40: 181-193.

54 Waran N, Best L, Williams V, et al. A preliminary study of behavior-based indicators of pain in cats. Anim Welf 2007; 16: 105-108.

55 Väisänen MA, Tuomikoski SK and Vainio OM. Behavioral alterations and severity of pain in cats recovering at home following elective ovariohysterectomy or castration. J Am Vet Med Assoc 2007; 231: 236-242.

56 Cagnardi P, Villa R, Zonca A, et al. Pharmacokinetics, intraoperative effect and postoperative analgesia of tramadol in cats. Res Vet Sci 2011; 90: 503-509.

57 Ravasio G, Gallo M, Beccaglia M, et al. Evaluation of a ketamine-propofol drug combination with or without dexmedetomidine for intravenous anaesthesia in cats undergoing overiectomy. J Am Vet Med Assoc 2012; 10: 1307-1313.

58 Robinson DA, Romans CW, Gordon-evans WJ, et al. Evaluation of short-term limb function following unilateral carbon dioxide laser or scalpel onychectomy in cats. J Am Vet Med Assoc 2007; 230: 353-358.

59 Curcio K, Bidwell LA, Bohart GV, et al. Evaluation of signs of postoperative pain and complications after forelimb onychectomy in cats receiving buprenorphine alone or with bupivacaine administered as a four-point regional nerve block. J Am Vet Med Assoc 2006; 228: 65-68.

60 Gellasch KL, Kurse-Elliot KT, Osmond CS, et al. Comparison of transdermal administration of fentanyl versus intramuscular administration of butorphanol for analgesia after onychectomy in cats. J Am Vet Med Assoc 2002; 220: 1020-1024.

61 Mison MB, Borhart GH, Walshaw R, et al. Use of carbon dioxide laser for onychectomy in cats. J Am Vet Med Assoc 2002; 5: 651-653.

62 Ingwersen W, Fox R, Cunningham G, et al. Efficacy and safety of 3 versus 5 days of meloxicam as an analgesic for feline onychectomy and sterilization. Can Vet J 2012; 53: 257-264.

63 Carroll GL, Howe LB and Peterson KD. Analgesic efficacy of preoperative administration of meloxicam or butorphanol in onychectomized cats. J Am Vet Med Assoc 2005; 226: 913-919.

64 Franks JN, Boothe HW, Taylor L, et al. Evaluation of transdermal fentanyl patches for analgesia in cats undergoing onychectomy. J Am Vet Med Assoc 2000; 217: 1013-1020.

65 Kipfer NM and Montavon PM. Fixation of pelvic floor fractures in cats. Vet Comp Orthop Traumatol 2011; 24: 137-141.

66 Murison PJ, Tacke S, Wondratschek C, et al. Postoperative analgesic efficacy of meloxicam compared to tolfenamic acid in cats undergoing orthopaedic surgery. J Small Anim Pract 2010; 51: 526-532.

67 Taylor PM, Kirby JJ, Robinson C, et al. A prospective multicentre clinical trial to compare buprenorphine and butorphanol for postoperative analgesia in cats. J Feline Med Surg 2010; 12: 247-255. 
68 Stanway GW, Taylor PM and Brodbelt DC. A preliminary investigation comparing pre-operative morphine and buprenorphine for postoperative analgesia and sedation in cats. Vet Anaesth Analg 2002; 29: 29-35.

69 McSweeney PM, Martin DD, Ramsey DS, et al. Clinical efficacy and safety of dexmedetomidine used as a preanesthetic prior to general anesthesia in cats. J Am Vet Med Assoc 2012; 4: 404-412.

70 Wagner KA, Gibbon KJ, Strom TL, et al. Adverse effects of EMLA (lidocaine/prilocaine) cream and efficacy for the placement of jugular catheters in hospitalized cats. J Feline Med Surg 2006; 8: 141-144.

71 Steagall PVM, Mantovani FB, Taylor PM, et al. Dose-related antinociceptive effects of intravenous buprenorphine in cats. Vet J 2009; 182: 203-209.

72 Castro DS, Silva MF, Shih AC, et al. Comparison between the analgesic effects of morphine and tramadol delivered epidurally in cats receiving a standardized noxious stimulation. J Feline Med Surg 2009; 11: 948-953.

73 Dixon MJ, Taylor PM, Steagall PVM, et al. Development of a pressure nociceptive threshold testing device for evaluation of analgesics in cats. Res Vet Sci 2007; 82: 85-92.

74 Taylor PM, Robertson SA and Dixon MJ. Evaluation of the use of thermal thresholds to investigate NSAID analgesia in a model of inflammatory pain in cats. J Feline Med Surg 2007; 9: 313-318.

75 Steagall PVM, Carnicelli P, Taylor PM, et al. Effects of subcutaneous methadone, morphine, buprenorphine or saline on thermal and pressure thresholds in cats. J Vet Pharmacol Ther 2006; 29: 531-537.

76 Benito J, Gruen ME, Thomson A, et al. Owner-assessed indices of quality of life in cats and the relationship to the presence of degenerative joint disease. J Feline Med Surg 2012; 14: 863-870.

77 Steagall PVM, Taylor PM, Brondani JT, et al. Effects of buprenorphine, carprofen and saline on thermal and mechanical nociceptive thresholds in cats. Vet Anae Anal 2007; 34: 344-350.

78 Ferreira TH, Rezende ML, Mama KR, et al. Plasma concentrations and behavioral, antinociceptive, and physiologic effects of methadone after intravenous and oral transmucosal administration in cats. Am J Vet Res 2011; 72: 764-771.

79 Johnson JA, Robertson SA and Pypendop BH. Antinociceptive effects of butorphanol buprenorphine or both administrated intramuscularly in cats. Am J Vet Res 2007; 68: 699-703.

80 Giraudel JM, King JN, Jeunesse EC, et al. Use of a pharmacokinetic/pharmacodynamic approach in the cat to determine a dosage regimen for the COX-2 selective drug robenacoxib. J Vet Pharmacol Ther 2009; 32: 18-30.

81 Murrell JC, Robertson S, Taylor PM, et al. Use of a transdermal matrix patch of buprenorphine in cats: preliminary pharmacokinetic and pharmacodynamic data. Vet Rec 2007; 160: 578-583.

82 Taylor PM, Steagall PVM, Dixon MJ, et al. Carprofen and buprenorphine prevent hyperalgesia in a model of inflammatory pain in cats. Res Vet Sci 2007; 83: 369-375.

83 Lascelles BDX and Robertson SA. Use of thermal threshold response to evaluate the antinociceptive effects of butorphanol in cats. Am J Vet Res 2004; 64: 1085-1099.
84 Giraudel JM, Diquelou A, Laroute V, et al. Pharmacokinetic/pharmacodynamic modelling of NSAIDs in a model of reversible inflammation in the cat. Br J Pharmacol 2005; 146: 642-653.

85 Slingsby LS, Murrell JC and Taylor PM. Combination of dexmedetomidine with buprenorphine enhances the antinociceptive effect to a thermal stimulus in the cat compared with either agent alone. Vet Anaesth Analg 2010; 37: 162-170.

86 Pypendop BH, Ilkiw JE and Robertson SA. Effects of intravenous administration of lidocaine on the thermal threshold in cats. Am J Vet Res 2006; 67: 16-20.

87 Pypendop BH, Siao KT and Ilkiw JE. Effects of tramadol hydrochloride on the thermal threshold in cats. Am J Vet Res 2009; 70: 1465-1470.

88 Ambros B, Steagall PVM, Mantovani F, et al. Antinociceptive effects of epidural administration of hydromorphone in conscious cats. Am J Vet Res 2009; 70: 1187-1192.

89 Pypendop BH, Pascoe PJ and Ilkiw JE. Effects of epidural administration of morphine and buprenorphine on the minimum alveolar concentration of isoflurane in cats. Am J Vet Res 2006; 67: 1471-1475.

90 Robertson SA, Taylor PM, Lascelles BD, et al. Changes in thermal threshold response in eight cats after administration of buprenorphine, butorphanol and morphine. Vet Rec 2003; 153: 462-465.

91 Robertson SA, Lascelles BD, Taylor PM, et al. PK-PD modeling of buprenorphine in cats: intravenous and oral transmucosal administration. J Vet Pharmacol Ther 2005; 28: 453-460.

92 Steagall PVM, Taylor PM, Brondani JT, et al. Antinociceptive effects of tramadol and acepromazine in cats. J Feline Med Surg 2008; 10: 24-31.

93 Wegner K, Robertson SA, Kollias-Baker C, et al. Pharmacokinetic and pharmacodynamic evaluation of intravenous hydromorphone in cats. J Vet Pharmacol Ther 2004; 27: 329-336.

94 Steagall PVM, Millette V, Mantovani FB, et al. Antinociceptive effects of epidural buprenorphine or medetomidine, or the combination, in conscious cats. J Vet Pharmacol Ther 2009; 32: 477-484.

95 Millette VM, Steagall PVM, Duke-Novaski T, et al. Effects of meperidine or saline on thermal, mechanical and electrical nociceptive threshold in cats. Vet Anaesth Analg 2008; 35: 543-547.

96 Siao KT, Pypendop BH, Escobar A, et al. Effect of amantadine on oxymorphone-induced thermal antinociception. J Vet Pharmacol Ther 2011; 35: 169-174.

97 Farnworth MJ, Barrett LA, Adams NJ, et al. Body weight affects behavioural indication of thermal nociceptive threshold in adult domestic cats (Felis catus). Appl Anim Behav Sci 2013; 149: 30-35.

98 Jiwlawat $S$ and Durongphontgtorn $S$. The antinociceptive effects of tramadol on the thermal threshold response in cats. Thai J Vet Med 2011; 41: 171-177.

99 Steagall PVM, Pellingand L, Giordano T, et al. Pharmacokinetic and pharmacodynamic modelling of intravenous, intramuscular and subcutaneous buprenorphine in conscious cats. Vet Anaesth Analg 2013; 40: 83-95.

100 Slingsby LS and Taylor PM. Thermal antinociception after dexmedetomidine administration in cats: a dose-finding study. J Vet Pharmacol Ther 2008; 31: 135-142. 
101 Farnworth MJ, Beausoleil NJ, Adams NJ, et al. Validating the use of a carbon dioxide laser for assessing nociceptive threshold in adult domestic cats (Felis catus). Appl Anim Behav Sci 2013; 143: 104-109.

102 Robertson SA, Taylor PM, Sear JW, et al. Relationship between plasma concentration and analgesia after intravenous fentanyl and disposition after other routes of administration in cats. J Vet Pharmacol Ther 2005; 28: 87-93.

103 Robertson SA, Wegner K and Lascelles BDX. Antinociceptive and side-effects of hydromorphone after subcutaneous administration in cats. J Feline Med Surg 2009; 11: 76-81.

104 Harris JE and Dhupa S. Lumbosacral intervertebral disk disease in six cats. J Am Anim Hosp Assoc 2008; 44: 109-115.

105 Guillot M, Moreau M, Heit M, et al. Characterization of osteoarthritis in cats and meloxicam efficacy using objective chronic pain evaluation tools. Vet J 2013; 196: 360-367.

106 Morton CM, Grant D, Johnston L, et al. Clinical evaluation of meloxicam versus ketoprofen in cats suffering from painful acute locomotor disorders. J Feline Med Surg 2011; 13: 237-243.

107 Lascelles BDX, DePuy V, Thomson A, et al. Evaluation of a therapeutic diet for feline degenerative joint disease. J Vet Intern Med 2010; 24: 487-495.

108 Gunew MN, Menrath VH and Marshall RD. Long-term safety, efficacy and palatability of oral meloxicam at $0.01-0.03 \mathrm{mg} / \mathrm{kg}$ for treatment of osteoarthritic pain in cats. J Feline Med Surg 2008; 10: 235-241.

109 Giraudel JM, Gruet PG, Alexander DG, et al. Evaluation of orally administered robenacoxib versus ketoprofen for treatment of acute pain and inflammation associated with musculoskeletal disorders in cats. Am J Vet Res 2010; 71: 710-719.

110 Lascelles BDX, Hansen BD, Roe S, et al. Evaluation of client-specific outcome measures and activity monitoring to measure pain relief in cats with osteoarthritis. J Vet Intern Med 2007; 21: 410-416.

111 Benito J, Hansen B, DePuy V, et al. Feline musculoskeletal pain index: responsiveness and testing of criterion validity. J Vet Intern Med 2013; 27, 474-482.

112 Lascelles BD, Henderson AJ and Hackett IJ. Evaluation of the clinical efficacy of meloxicam in cats with painful locomotor disorders. J Small Anim Pract 2001; 42: 587-593.

113 Zamprogno $\mathrm{H}$, Hansen BD, Bondell HD, et al. Item generation and design testing of a questionnaire to assess degenerative joint disease-associated pain in cats. Am J Vet Res 2010; 71: 1417-1424.

114 Klinck MP, Frank D, Guillot M, et al. Owner-perceived signs and veterinary diagnosis in $\mathbf{5 0}$ cases of feline osteoarthritis. Canadian Vet J 2012; 53: 1181-1186.
115 Slingerland LI, Hazewinkel HAW, Meij BP, et al. Crosssectional study of the prevalence and clinical features of osteoarthritis in 100 cats. Vet J 2011; 187: 304-309.

116 Engelen M and Anthonissens E. Efficacy of non-acaricidal containing otic preparations in the treatment of otoacariasis in dogs and cats. Vet Rec 2000; 147: 567-569.

117 Gerber B, Boretti FS, Kley FS, et al. Evaluation of clinical signs and causes of lower urinary tract disease in European cats. J Small Anim Pract 2005; 46: 571-577.

118 Carroll GL, Narbe R, Kerwin SC, et al. Dose range finding study for the efficacy of meloxicam administered prior to sodium urate-induced synovitis in cats. Vet Anaesth Analg 2011; 38: 394-406.

119 Wegner K and Robertson SA. Dose-related thermal antinociceptive effects of intravenous hydromorphone in cats. Vet Anaesth Analg 2007; 34: 132-138.

120 Hellyer P, Rodan I, Brunt J, et al. AAHA/AAFP pain management guidelines for dogs and cats. Vet Surg 2007; 9: 466.

121 Bieri D, Reeve RA, Champion GD, et al. The faces pain scale for the self-assessment of the severity of pain experienced by children: development, initial validation, and preliminary investigation for ratio scale properties. Pain 1990; 41: 139-150.

122 Langford DJ, Bailey AL, Chanda ML, et al. Coding of facial expressions of pain in the laboratory mouse. Nat Methods 2010; 7: 447-449.

123 Le Bars D, Gozariu M and Cadden SW. Animal models of nociception. Pharmacol Rev 2001; 53: 597-652.

124 Meintjes R. An overview of the physiology of pain for the veterinarian. Vet J 2012; 193: 344-348.

125 Millan MJ. The induction of pain: an integrative review. Prog Neurobiol 1999; 57: 1-164.

126 Rutherford KMD. Assessing pain in animals. Anim Welf 2002; 11: 31-53.

127 Robertson SA. Managing pain in feline patients. Vet Clin N Am Small 2008; 38: 1267-1290.

128 Roughan JV and Flecknell PA. Evaluation of a short duration behaviour-based postoperative pain scoring system in rats. Eur J Pain 2003; 7: 397-406.

129 Prunier A, Mounier L, Le Neindre P, et al. Identifying and monitoring pain in farm animals: a review. Animal 2013; 7: 998-1010.

130 Mills DS, Karagiannis C and Zulch H. Stress - its effects on health and behavior: a guide for practitioners. Vet Clin N Am Small 2014; 44: 525-541.

131 Scherer KR. On the nature and function of emotion: a component process approach. In: Scherer KR and Ekman P (eds). Approaches to emotion. Hillsdale, NJ: Erlbaum, 1984, pp 293-317. 